\title{
Review Article/Brief Review
}

\section{Ultrasonography and stimulating perineural catheters for nerve blocks: a review of the evidence}

\author{
[L'échographie et les cathéters périneuraux stimulants pour les blocs nerveux : une \\ synthèse des données probantes]
}

De Q.H. Tran MD FRCPC, Loreto Muñoz MD, Gianluca Russo MD, Roderick J. Finlayson MD FRCPC

Purpose: This narrative review summarizes the evidence derived from randomized controlled trials (RCTs) offering blinded assessment and sample size justification, in order to determine the benefits associated with adjunctive ultrasonography (US) and stimulating perineural catheters for nerve blocks.

Source: The literature search for this review was conducted during the second week of December 2007 using the MEDLINE (January 1950 to November 2007) and EMBASE (January 1980 to November 2007) databases. For US-guided peripheral and neuraxial blocks, the following medical subject heading (MeSH) terms were searched: "nerve block", "epidural anesthesia", "epidural analgesia”, "epidural injection”, "epidural space”, "spinal anesthesia", and "spinal injection", the results were combined with "ultrasonography" (MeSH term) and "ultrasound" (key word). For stimulating perineural catheters, the following MeSH terms were cross referenced with the MeSH term, "nerve block": "peripheral catheterization", "indwelling catheterization", "catheterization", and keywords, "nerve catheter" and "continuous". Subsequently, the result of this search was combined to "stimulating" (key word). Fifteen RCTs, offering blinded assessment and sample size justification, were retained for analysis.

Principal findings: For axillary blocks, US guidance yields a higher success rate than a double-injection, transarterial and a triple-injection, neurostimulation-guided technique. Compared to a quadruple-stimulation technique, no major differences can be found. The addition of nerve stimulation to US guidance offers no clear benefits for axillary blocks. For femoral blocks, compared to neurostimulation, echoguidance is associated with a local anesthetic (LA) sparing effect (up to $42 \%$ ). In children,
US guidance yields a LA sparing effect and a longer duration of action for lower extremity nerve blocks.

Compared to their blind counterparts, stimulating catheters seem to offer limited clinical benefits. Despite providing a sparing effect on LA and opioid consumption, stimulating catheters are not associated with a decrease in side effects or analgesiarelated expenditures.

Conclusions: Published reports of RCTs provide evidence to formulate limited recommendations regarding the use of adjunctive US and stimulating perineural catheters. Further welldesigned and meticulously executed RCTs are warranted.

CAN J ANESTH $2008 / 55: 7 /$ pp 447-457

Objectif: Cette synthèse narrative résume les données probantes tirées d'études randomisées contrôlées (ERC) disposant d'une évaluation en aveugle et de justification de la taille de l'échantillon afin d'identifier les bienfaits associés à une utilisation conjointe de l'échographie et de cathéters périneuraux stimulants lors de blocs nerveux.

Sources : La recherche de littérature pour cet article de synthèse $a$ été menée la deuxième semaine de décembre 2007 dans les bases de données MEDLINE (janvier 1950 à novembre 2007) et EMBASE (janvier 1980 à novembre 2007). Pour les blocs périphériques et neuraxiaux échoguidés, les termes MeSH suivants ont été recherchés : "nerve block», "epidural anesthesia», "epidural analgesia », " epidural injection », " epidural space », "spinal anesthesia » et "spinal injection", et ont été associés à "ultrasonography"

From the Department of Anesthesia, Montreal General Hospital, McGill University, Montreal, Quebec, Canada. Address correspondence to: Dr. De Q.H. Tran, Montreal General Hospital, Department of Anesthesia, 1650 Ave Cedar, D10-144,

Montreal, Quebec H3G 1A4, Canada. Phone: 514-934-1934 ext. 43261; Fax: 514-934-4289; E-mail: de_tran@hotmail.com Competing interests: None declared.

Accepted for publication February 26, 2008.

Revision accepted March 26, 2008. 
(terme MeSH) et " ultrasound " (mot clé). Pour les cathéters périneuraux stimulants, les termes MeSH suivants ont été croisés avec le terme MeSH "nerve block»: "peripheral catheterization", "indwelling catheterization", " catheterization », et les mots clés " nerve catheter » et " continuous ». Ensuite, les résultats de cette recherche ont été combinés avec le mot clé « stimulating ». Quinze ERC disposant d'une évaluation en aveugle et de justification de la taille de l'échantillon ont été retenues pour être analysées.

Constatations principales: Dans le cas de blocs axillaires, l'échoguidage offre un meilleur taux de réussite qu'une technique de double injection transartérielle et qu'une technique de triple injection guidée par neurostimulation. Si on compare l'échoguidage à une technique de quadruple stimulation, aucune différence majeure n'apparaît. L'ajout de stimulation nerveuse à l'échoguidage ne procure pas de bienfaits clairs dans le cas des blocs axillaires. Lorsqu'un bloc fémoral est réalisé, l'échoguidage est associé à un besoin moindre en anesthésique local (AL) (jusqu'à $42 \%$ ) par rapport à la neurostimulation. Chez les enfants, l'échoguidage résulte en un besoin moindre en anesthésique local et une durée prolongée d'action pour les blocs nerveux des membres inférieurs.

Par rapport à leurs pendants aveugles, les cathéters stimulants semblent n'offrir que des bienfaits cliniques limités. Malgré le fait qu'ils génèrent un besoin moins important en anesthésiques locaux et réduisent la consommation d'opioïdes, les cathéters stimulants ne sont pas associés à une réduction des effets secondaires ou des coûts liés à l'analgésie.

Conclusion : Les comptes-rendus publiés d'ERC fournissent des données probantes qui peuvent encourager la formulation de recommandations limitées quant à l'utilisation conjointe d'échoguidage et de cathéters périneuraux stimulants. D'autres ERC bien conçues et menées avec soin sont justifiées.

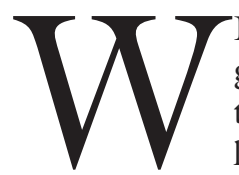

ITHIN the last ten years, the field of regional anesthesia has undergone a major transformation. The widespread use of low molecular weight heparins and the implementation of outpatient surgery have compelled anesthesiologists to rethink postoperative pain control and to favour nerve blocks over traditional analgesic modalities. However, like any other technical field, the development of regional anesthesia necessitated a parallel improvement in the equipment available. Thus, the introduction into clinical practice of adjunctive ultrasonography (US) and stimulating perineural catheters has clearly contributed to the specialty's increasing popularity. US has revolutionized the practice of regional anesthesia by allowing the operator to visualize, in real time, the nerve, the needle and, more importantly, the spread of local anesthetic (LA) agents. Stimulating perineural catheters have contributed to decrease the failure rate of blind (i.e., non stimulating) catheters, thus, theoretically improving postoperative analgesia for the patient. Despite this enthusiasm, many issues pertaining to the efficacy of these new tools remain ambiguous. Accordingly, a literature search for the best available evidence (randomized controlled trials with adequate blinded assessment and sample size justification) was undertaken, to determine if US is superior to other adjunctive modalities and if stimulating catheters are associated with better clinical outcomes than non stimulating catheters.

\section{Methods}

\section{Search strategy and selection criteria}

The literature search for this review was conducted during the second week of December 2007 using the MEDLINE (January 1950 to the second week of November 2007) and EMBASE (January 1980 to the $49^{\text {th }}$ week of 2007) databases.

For US-guided peripheral nerve blocks, the medical subject heading ( $\mathrm{MeSH})$ term, "nerve block", was searched using the operator, "and". It was then combined with the MeSH term, "ultrasonography", as well as the key word, "ultrasound". For US-guided neuraxial blocks, MeSH terms; "epidural anesthesia", "epidural analgesia", "epidural injection", "epidural space", "spinal anesthesia", and "spinal injection" were also combined with "ultrasonography" ( $\mathrm{MeSH}$ term) and "ultrasound" (key word) using the operator, "and".

For stimulating perineural catheters, using the operator, "or", MeSH terms, "peripheral catheterization", "indwelling catheterization", "catheterization", and keywords, "nerve catheter" and "continuous" were combined together. The result of this search was then cross referenced with the MeSH term, "nerve block", using "and". Subsequently, the result of this second search was combined to "stimulating" (key word) using the operator, "and".

The final results of these two initial searches were limited to peer-reviewed reports of human studies. Only randomized controlled trials (RCTs) comparing US to traditional, adjunctive modalities and stimulating to non stimulating perineural catheters were retained. Furthermore, only RCTs with blinded assessments and appropriate sample size justification were considered. After selecting the initial articles, we examined the reference lists, as well as our personal files, for additional material. No RCTs were excluded, based on factors such as definition of intervention, method of allocation concealment, or separation of primary and secondary outcomes. However, nonrandomized studies, observational case reports, and 


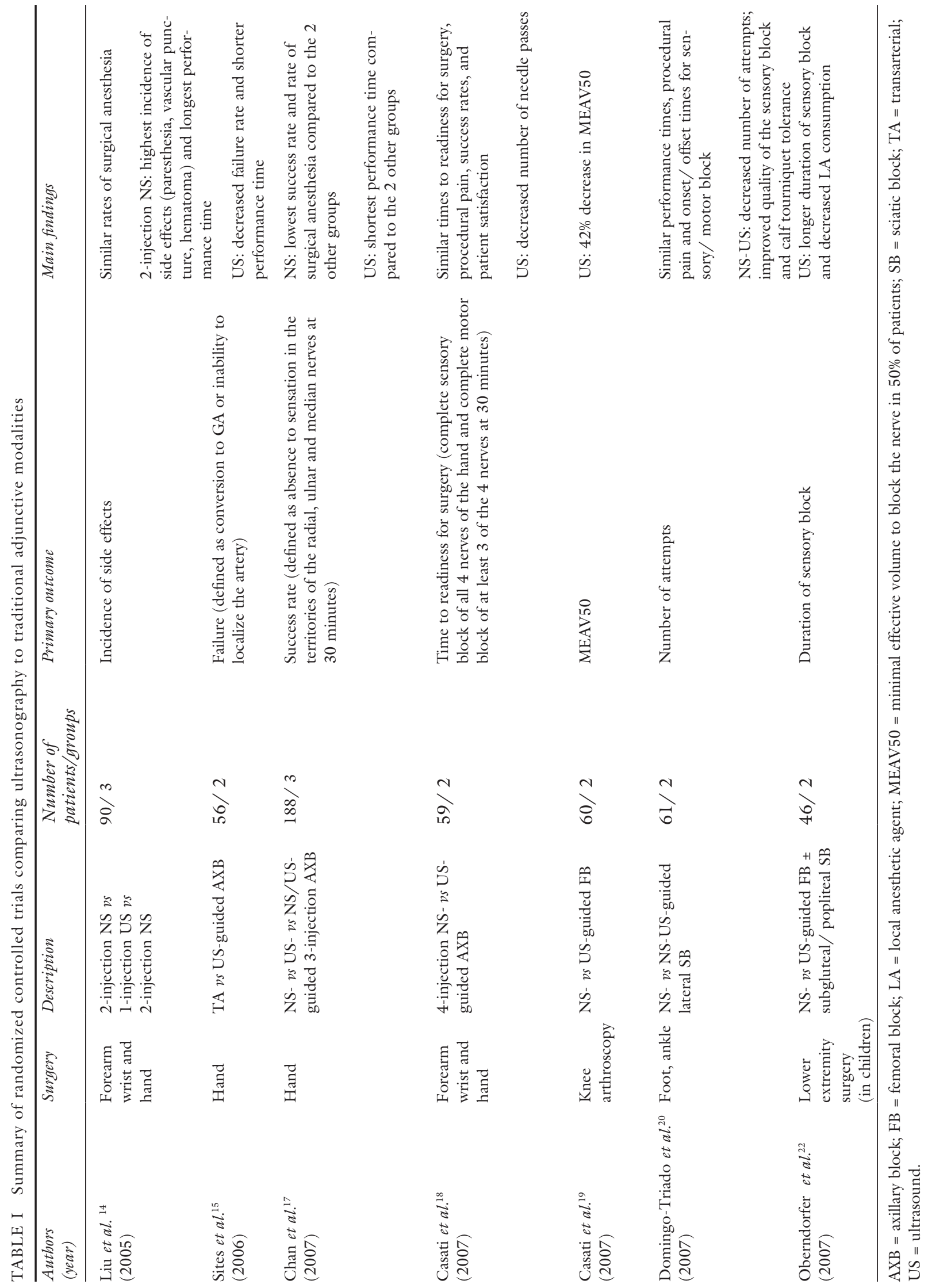




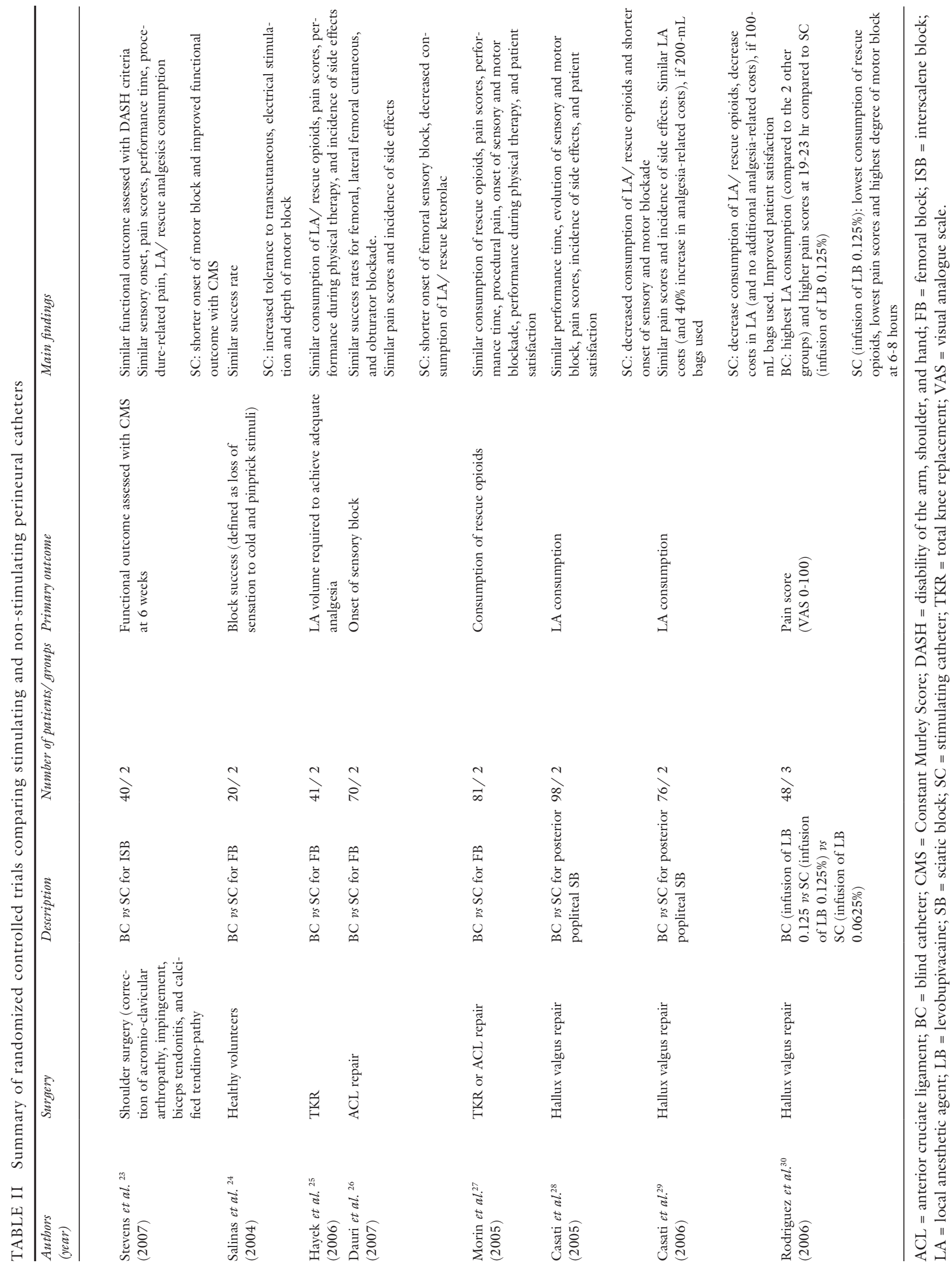


cohort studies were excluded, to avoid potential biases introduced by institutional practices.

\section{Results}

Our search criteria yielded 28 RCTs. Of these studies, 13 were excluded because they did not provide blinded assessment or sample size justification. ${ }^{1-13}$ Of the remaining 15 RCTs, seven compared US to traditional adjunctive modalities for peripheral nerve blocks (Table I), while eight compared stimulating to non-stimulating perineural catheters (Table II).

\section{Adjunctive ultrasonography} Axillary block ( $A X B)$

Four RCTs have compared AXB using traditional adjuncts and US. Liu et al. ${ }^{14}$ randomized 90 patients undergoing forearm/ hand surgery to an AXB. They used a two-injection, neurostimulation-guided technique, with equal volume injections around the median and radial nerves (stimulation thresholds and pulse widths not specified); a one-injection, US technique (with injection around the lateral aspect of the axillary artery); and a two-injection, US technique (with equal volume injections around the lateral and the medial aspects of the artery). All subjects received $0.5 \mathrm{~mL} \cdot \mathrm{kg}^{-1}$ of lidocaine $1.5 \%$ with epinephrine 5 $\mu \mathrm{g} \cdot \mathrm{mL}^{-1}$. Compared to the US groups, these authors reported a longer performance time $(8.2 \pm 1.5$ vs 6.5$6.7 \pm 1.3 \mathrm{~min} ; P<0.05)$ and a higher incidence of side effects (paresthesia, vascular puncture, hematoma) (20 vs $0 \%$ of patients; $P=0.03$ ) with neurostimulation. However, no differences were noted in success of surgical anesthesia $(83-90 \%)$ and in the rate of complete blocks at $40 \mathrm{~min}(70-73 \%)$. Despite the fact that one important benefit of US-guided nerve block resides in the visualization of LA spread and the repositioning of the needle tip to achieve circumferential, perivascular or perineural spread, Liu et al. ${ }^{14}$ elected to keep the needle in a static position during the injection for their two US groups. This may explain the lack of difference in success rates between US and neurostimulation (NS). Using a technique relying on multiple injections to achieve circumferential LA spread around the artery, Sites et $a l .{ }^{15}$ compared US guidance to a transarterial technique (with two equal volume injections in front and behind the artery) in 56 patients undergoing hand surgery. Using $35 \mathrm{~mL}$ of lidocaine $1.5 \%$ with epinephrine $5 \mu \mathrm{g} \cdot \mathrm{mL}^{-1}$, these authors found that echoguidance yielded a shorter performance time $(7.9 \pm 3.9$ vs $11.1 \pm 5.7 \mathrm{~min} ; P<0.05)$ and a lower failure rate, defined as conversion to general anesthesia or the inability to localize the artery ( 0 vs $28.6 \%$ of patients; $P=0.01)$. The low success rate of the transarterial technique echoes the findings of a recent review article, which reported that, for AXB, a three- or four-NS technique offers the highest efficacy. ${ }^{16}$ Thus, after enrolling 188 patients undergoing hand surgery, Chan et al. ${ }^{17}$ performed a three-injection AXB (with injections around the median, radial, and ulnar nerves) and randomized the adjunctive technique to NS, US, or NS combined with US. All patients received $42 \mathrm{~mL}$ of an adrenalized, equal-part mix of lidocaine $2 \%$ and bupivacaine $0.5 \%$. For the NS and the NS-US groups, a stimulation threshold of $0.5 \mathrm{~mA}$ or less (pulse width $=0.1 \mathrm{msec}$ ) was deemed satisfactory. Forearm pronation/ thumb opposition, fourth/ fifth finger flexion, and forearm/ wrist extension were considered acceptable motor responses for stimulation of the median, ulnar, and radial nerves, respectively. These authors found that patients in the NS group displayed the lowest success rate (defined as the absence of tactile sensation in all three nerve territories at $30 \mathrm{~min})(62.9$ vs $80.7-82.8 \%$ of patients; $P=0.03)$. Subjects in the US and the US-NS groups exhibited similar success rates and incidences of surgical anesthesia (92-95\%). However, the addition of NS to US resulted in a longer performance time $(12.4 \pm 4.8$ vs $9.3 \pm 4 \mathrm{~min}$; $P=0.01)$. There were no differences in the incidence of side effects. In 59 patients undergoing upper limb surgery below the elbow, Casati et al. ${ }^{18}$ compared a four-injection $\mathrm{AXB}$ using NS or US. All subjects received $5 \mathrm{~mL}$ of ropivacaine $0.75 \%$ per nerve. For patients randomized to NS, a stimulation threshold of $0.5 \mathrm{~mA}$ or less (pulse width $=0.15 \mathrm{msec}$ ) was required for each nerve. Wrist/ second and third finger flexion, fourth and fifth finger flexion, forearm/ finger extension, and forearm flexion were considered acceptable motor responses for stimulation of the median, ulnar, radial, and musulocutaneous nerves, respectively. Despite a shorter onset of sensory blockade in the US group, these authors reported no difference in readiness for surgery (defined as complete sensory block in the four nerve territories and complete motor block in at least three nerve territories) (26-28 min). No failed block was reported in either group. Furthermore, procedural pain scores and patient satisfaction were also similar.

\section{Femoral block (FB)}

In 60 patients requiring $\mathrm{FB}$ (using ropivacaine $0.5 \%$ ) for knee arthroscopy, after randomizing the technique to NS or US, Casati et al. ${ }^{19}$ set out to elucidate the minimum effective anesthetic volume (MEAV). Starting with an initial volume of $12 \mathrm{~mL}$, LA volume was decreased by $3 \mathrm{~mL}$ in each subsequent patient if effective femoral nerve block was achieved within 30 
min of injection. Conversely, LA volume was increased by $3 \mathrm{~mL}$ in the subsequent patient, if a failure occurred. For NS, a stimulation threshold of $0.4 \mathrm{~mA}$ or less (pulse width $=0.05 \mathrm{msec}$ ) and quadricipital contraction (with patellar movement), as the evoked motor response, were sought. These authors found a $42 \%$ reduction in LA requirement with US; the MEAV50 were $15 \pm 4$ and $26 \pm 4 \mathrm{~mL}$ for US and NS, respectively $(P=0.002)$. The effective dose in $95 \%$ of cases $\left(\mathrm{ED}_{95}\right)$, through probit transformation and logistic regression analysis, was calculated to be 22 and 41 $\mathrm{mL}$, for US and NS, respectively.

\section{Sciatic block (SB)}

In 61 patients undergoing foot or ankle surgery, Domingo-Triado et al. ${ }^{20}$ performed a lateral, midfemoral SB using $35 \mathrm{~mL}$ of ropivacaine $0.5 \%$. They randomized the adjunctive technique to isolated NS or US-NS. Despite the fact that one important benefit of US-guided nerve block resides in the visualization of LA spread and the repositioning of the needle tip to achieve circumferential perineural spread, these authors used US mainly to guide the stimulating needle towards the nerve. Moreover, despite the fact that tibial nerve electrostimulation is associated with a higher success rate for lateral, midfemoral SB,${ }^{21}$ both tibial and peroneal nerve stimulation were deemed satisfactory endpoints. A saphenous nerve block was also performed when the surgical incision extended over the saphenous nerve's innervation area. For $\mathrm{SB}$, both groups displayed a similar median stimulating threshold $(0.5 \mathrm{~mA}$; pulse width $=0.3 \mathrm{msec})$. In the NS group, stimulation of the posterior tibial nerve occurred more often (58 vs $30 \%$ of patients; $P=0.04)$. Despite this, more patients in the US-NS group displayed a complete sensory block (96.7 ps $71 \%$ of patients; $P=0.01$ ) and tolerance to calf tourniquet ( 93.3 vs $48.4 \%$ of patients; $P=0.001$ ). There were no significant differences in procedural pain, performance time, sensory and motor block onset times, or block duration. In 46 pediatric patients undergoing lower extremity surgery, Oberndorfer et al. ${ }^{22}$ performed isolated $\mathrm{SB}(n=32)$ or $\mathrm{SB}$ combined with $\mathrm{FB}$ $(n=14)$. They randomized the adjunctive technique to US or NS. Sciatic block was carried out using the subgluteal $(n=23)$ or the popliteal $(n=23)$ approaches. For neurostimulation of the sciatic nerve, a minimal, stimulation threshold of $0.3 \mathrm{~mA}$ or less (pulse width $=0.3 \mathrm{msec}$ ) and plantar flexion, as the evoked motor response, were deemed satisfactory. For stimulation of the femoral nerve, a minimal stimulation threshold of $0.3 \mathrm{~mA}$ or less (pulse width $=$ $0.3 \mathrm{msec}$ ) and quadricipital contraction, as the evoked motor response, were sought. For US-guided SB and $\mathrm{FB}$, the authors used a multiple-injection technique to achieve circumferential LA spread around the nerve. All subjects received levobupivacaine $0.5 \%$, either at a fixed dose of $0.3 \mathrm{~mL} \cdot \mathrm{kg}^{-1}$ per nerve (NS group), or until the target nerve was surrounded by LA (US group). Despite receiving a lower amount of LA for both SB $\left(0.20 \pm 0.06\right.$ vs $\left.0.3 \mathrm{~mL} \cdot \mathrm{kg}^{-1} ; P<0.001\right)$ and FB $\left(0.15 \pm 0.04\right.$ vs $\left.0.3 \mathrm{~mL} \cdot \mathrm{kg}^{-1} ; P<0.01\right)$, patients in the US group had longer lasting blocks $(508 \pm 178$ ps $335 \pm 169 \mathrm{~min} ; P<0.001)$.

\section{Interpretation}

In the setting of $\mathrm{AXB}$, multiple-injection US guidance yields a higher success rate compared to a doubleinjection, transarterial and a three-NS technique. Compared to a four-NS technique, both methods result in similar success rates, procedural pain scores, readiness for surgery, and patient satisfaction. The addition of NS to US guidance offers no clear benefits for AXB; in fact, a marginally longer performance time $(3.1 \mathrm{~min})$ is seen when both modalities are combined. In the setting of $\mathrm{FB}$, compared to NS, echoguidance is associated with a LA sparing effect (up to $42 \%$ ). In children, US guidance yields a LA sparing effect and a longer duration of action for lower extremity nerve blocks.

Because of the limited number of studies, caution should be exercised when interpreting the data available in the literature. So far, no RCT with blinded assessments and appropriate sample size justification, has investigated US as a substitute to NS, in the context of cervical paravertebral block, interscalene block, supraclavicular block, infraclavicular block, humeral canal block, lumbar plexus block, and SB, using approaches other than the subgluteal and posterior popliteal approaches. Furthermore, no RCT has compared US- and NS-guided continuous peripheral nerve blocks.

\section{Stimulating perineural catheters Interscalene block (ISB)}

In 40 patients undergoing corrective surgery for acromioclavicular arthropathy, impingement, biceps tendonitis, and calcified tendinopathy, Stevens et al. ${ }^{23}$ compared blind and stimulating interscalene catheters (median stimulation threshold of the catheter $=0.4$ $\mathrm{mA}$; pulse width $=0.1 \mathrm{msec}$ ). Both catheters were injected with $40 \mathrm{~mL}$ of prilocaine $1 \%$ and with 10 $\mathrm{mL}$ of ropivacaine $0.75 \%$ and were also infused with ropivacaine $0.2 \%\left(8 \mathrm{~mL} \cdot \mathrm{hr}^{-1}\right.$ with $2 \mathrm{~mL}$ each $20 \mathrm{~min}$ prn). During the study period ( $48 \mathrm{hr})$, these authors reported no differences in static and dynamic pain 
scores, ropivacaine consumption, and requests for supplemental non-steroidal, anti-inflammatory drugs (metimazol) or opioids (piritramide). Furthermore, procedural pain and performance time were also similar. However, complete motor block was achieved ten minutes sooner with stimulating catheters (10 vs 20 min; $P=0.02$ ); onset of sensory block did not differ between the two groups. At six months, patients who received a stimulating catheter displayed a greater improvement in shoulder function when assessed with the Constant Murley Score (34.5 vs 4; $P<0.01$ ), but not when assessed with the Disability of the Arm, Shoulder and Hand criteria.

\section{Femoral block (FB)}

Four RCTs have compared stimulating and non stimulating femoral catheters in healthy volunteers undergoing total knee replacement (TKR) and anterior cruciate ligament (ACL) repair. In 20 healthy volunteers, Salinas et al. ${ }^{24}$ placed bilateral femoral catheters by randomizing one side to a non stimulating catheter and the contralateral side to a stimulating catheter (mean stimulation threshold of the catheter $=$ $0.47 \pm 0.05 \mathrm{~mA}$; pulse width $=0.1 \mathrm{msec}$ ). Both catheters were bolused with $10 \mathrm{~mL}$ of lidocaine $1 \%$ and infused with ropivacaine $0.2 \%$ infusion $\left(10 \mathrm{~mL} \cdot \mathrm{hr}^{-1}\right.$ for four hours). These authors detected a clinical difference of $15 \%$ in success rate (i.e., loss of sensation to cold and pinprick) (85 vs $100 \%$ of patients; $P=0.07$ ); however, the protocol was only powered to detect a $25 \%$ difference. Nonetheless, limbs anesthetized with stimulating catheters displayed a denser femoral nerve block, as evidenced by higher tolerance to transcutaneous electrical stimulation $(P=0.009)$ and depth of motor impairment $(P=0.03)$.

In 41 patients undergoing unilateral TKR, Hayek et al. ${ }^{25}$ compared blind to stimulating femoral catheters (mean stimulation threshold of the catheter $=0.5$ $\pm 0.2 \mathrm{~mA}$; pulse width unspecified). Both catheters were injected with $25 \mathrm{~mL}$ of ropivacaine $0.2 \%$ and infused with $6 \mathrm{~mL} \cdot \mathrm{hr}^{-1}$ of ropivacaine $0.2 \%$ for $24-48$ hr. For breakthrough pain, both groups were allowed nurse-controlled boluses and increases in the rate of ropivacaine. They also had access to patient-controlled intravenous fentanyl. A single shot SB was not performed. These authors reported similar consumptions of ropivacaine $\left(8.2-8.8 \mathrm{~mL} \cdot \mathrm{hr}^{-1}\right)$ and fentanyl $\left(55.0-55.5 \mu \mathrm{g} \cdot \mathrm{hr}^{-1}\right)$. Furthermore, no differences were found in pain scores, block success rate, physical therapy performance, and side effects.

In 70 patients undergoing ACL repair, Dauri et al. ${ }^{26}$ compared blind and stimulating femoral catheters ( stimulation threshold of the catheter $=0.4-0.5$
$\mathrm{mA}$; pulse width $=0.1 \mathrm{msec}$ ). Both catheters were inserted preoperatively, and bolused with $25 \mathrm{~mL}$ of ropivacaine $0.75 \%$ and $50 \mu \mathrm{g}$ of clonidine. The 36-hr infusion consisted of ropivacaine $0.2 \%$ (7 $\mathrm{mL} \cdot \mathrm{hr}^{-1}$ with $5 \mathrm{~mL}$ each $60 \mathrm{~min}$ prn $)$. A single shot $\mathrm{SB}$ (using $20 \mathrm{~mL}$ of ropivacaine $0.75 \%$ and $50 \mu \mathrm{g}$ of clonidine) was also performed, to provide analgesia for the posterior aspect of the knee. Stimulating catheters resulted in a quicker sensory block for the femoral nerve $(6.4 \pm 2.5$ vs $8.3 \pm 2.9 \mathrm{~min} ; P=0.006)$; however, the success rates of femoral $(100 \%)$, lateral femoral cutaneous (74.3-88.6\%), and obturator nerve blockade (74.2-82.8\%) did not differ between the two groups. Furthermore, the intraoperative requirements of propofol and sufentanyl were also similar. Postoperatively, patients with stimulating catheters consumed less breakthrough ropivacaine $(14.6 \pm 12.6$ vs $23.2 \pm 13.6 \mathrm{mg} ; P=0.008)$ and rescue ketorolac $(34.3 \pm 35.7$ vs $54 \pm 39.7 \mathrm{mg} ; P=0.033)$. This did not translate into a reduced incidence of side effects. Moreover, static and dynamic pain scores were not significantly different.

In 81 patients undergoing TKR $(n=60)$ or ACL repair $(n=21)$, Morin et al. ${ }^{27}$ compared blind and stimulating femoral catheters (median stimulation threshold of the catheter $=0.2 \mathrm{~mA}$; pulse width $=$ $0.3 \mathrm{msec}$ ). Both catheters received a bolus of $20 \mathrm{~mL}$ of prilocaine $2 \%$ and an infusion of ropivacaine $0.2 \%$ $\left(6 \mathrm{~mL} \cdot \mathrm{hr}^{-1}\right.$ for $48 \mathrm{hr}$ ). All patients received a daily dose of rofecoxib and had access to patient-controlled narcotics (piritramide) for breakthrough pain. The authors did not perform a single shot SB. Morin et al. ${ }^{27}$ found no technical differences pertaining to catheter placement (procedural time, patient satisfaction, and anesthesiologist's evaluation of the difficulty encountered). After the bolus, no differences were noted in the onset of sensory and motor blockade. Postoperatively, static and dynamic pain scores, as well as physiotherapy performance, were similar during the five observational days after surgery. Although a $15 \%$ decrease in rescue piritramide consumption was noted during the first $48 \mathrm{hr}$ ( 44 vs $52 \mathrm{mg}$ ), this did not achieve statistical significance, as the protocol was only powered to detect a $33 \%$ difference.

\section{Sciatic block (SB)}

Three RCTs have compared stimulating and non stimulating, posterior popliteal sciatic catheters in the setting of hallux valgus surgery. In all three studies, a single shot femoral or saphenous nerve block was also performed, to cover the medial aspect of the lower limb. Patients also received regular doses of propacetamol or ketorolac. In 98 subjects, after bolusing the 
popliteal catheters with $25 \mathrm{~mL}$ of mepivacaine $1.5 \%$ and infusing them with ropivacaine $0.2 \%\left(3 \mathrm{~mL} \cdot \mathrm{hr}^{-1}\right.$ with $5 \mathrm{~mL}$ each $20 \mathrm{~min}$ prn to a maximum of two hourly doses), Casati et al. ${ }^{28}$ observed that stimulating catheters (mean stimulation threshold of the catheter $=0.39 \pm 0.17 \mathrm{~mA}$; pulse width $=0.15 \mathrm{msec}$ ) were associated with a shorter onset of sensory (15 vs $20 \mathrm{~min}$ for tibial nerve; 10 vs $15 \mathrm{~min}$ for common peroneal nerve; both $P \leq 0.02$ ) and motor blockade (20 vs $30 \mathrm{~min} ; P=0.004)$, as well as a decrease in ropivacaine consumption ( 239 vs $322 \mathrm{~mL} ; P=0.002$ ) and need for rescue opioid (tramadol) analgesia (25 vs $58 \%$ of patients; $P=0.002$ ). However, during the study period $(48 \mathrm{hr})$, this did not translate into a difference in the evolution sensory and motor blockade, the static and dynamic pain scores, or the incidence of side effects. Moreover, patient satisfaction was also similar. Interestingly, the catheter insertion time was not different between the two groups $(5-7 \pm 2$ $\mathrm{min})$. The following year, Casati et al. ${ }^{29}$ repeated the same protocol in another 76 patients. Again, during the study period $(24 \mathrm{hr})$, stimulating catheters (stimulation threshold not specified) were associated with a decrease in ropivacaine consumption (120 vs $153 \mathrm{~mL} ; P=0.04)$. Administration of breakthrough tramadol was also decreased (21 vs $60 \%$ of patients; $P=0.001)$. Despite yielding a marginally higher level of patient satisfaction (90 vs 80 on a $0-100 \mathrm{~mm}$ scale; $P=0.013)$, this altered neither the static and dynamic pain scores, nor the incidence of side effects. However, the authors were able to calculate that the reduction in ropivacaine resulted in decreased costs in LA (2l vs $42 \varepsilon ; P<0.001)$, if $100-\mathrm{mL}$ bags of ropivacaine were used. These savings covered the additional cost of the stimulating catheter so that, in the end, there were no differences in analgesia-related expenditures between the two groups. When using $200-\mathrm{mL}$ bags, the LA sparing effect did not occur; thus, a $40 \%$ increase in analgesia-related costs was seen with stimulating catheters $(75$ vs $55 \varepsilon ; P<0.001)$.

Rodriguez et al. ${ }^{30}$ randomized 48 patients to blind catheters using levobupivacaine $0.125 \%$ infusion, stimulating catheters using levobupivacaine $0.0625 \%$ infusion (median stimulatory threshold of the catheter $=0.52 \mathrm{~mA}$; pulse width $=0.1 \mathrm{msec}$ ), and stimulat ing catheters using levobupivacaine $0.125 \%$ infusion (median stimulatory threshold of the catheter $=0.42$ $\mathrm{mA}$; pulse width $=0.1 \mathrm{msec}$ ). All infusions were run at a basal rate of $3 \mathrm{~mL} \cdot \mathrm{hr}^{-1}$, with the possibility of one additional bolus of $3 \mathrm{~mL}$ every hour. These authors reported that the stimulating catheter-levobupivacaine $0.125 \%$ group consistently displayed lower pain scores at six to eight hours (5 ps 60-70 on a $0-100$ scale;
$P<0.05)$ and required less rescue opioid (tramadol) analgesia at $24 \mathrm{hr}(0 \mathrm{vs} 3 \mathrm{l}-44 \%$ of patients; $P<0.05)$. However, motor block of the ankle occurred more frequently at six to eight hours ( 88 vs $25-31 \%$ of patients; $P<0.05)$.

\section{Interpretation}

Compared to their blind counterparts, stimulating catheters can provide faster and denser nerve blocks. Although statistically significant, the shorter onset of sensory blockade (for instance, $6.4 \pm 2.5$ vs $8.3 \pm 2.9$ min for FB) may not be clinically relevant. Furthermore, these advantages do not seem to offer many practical benefits, because of their minimal impact on patient satisfaction, procedural pain, performance time, success rate of the block, static/ dynamic pain scores, and physiotherapy performance. Stimulating catheters can also provide a reduction in LA and opioid consumption. Unfortunately, this sparing effect is not associated with a decrease in the incidence of side effects. Furthermore, at best, the decrease in LA consumption may only serve to cover the cost of the stimulating catheter itself; total analgesia-related expenditures remain similar between stimulating and non stimulating catheters.

Caution should be exercised when interpreting the data available in the literature. So far, only a limited number of surgical procedures (shoulder, TKR, ACL, and hallux valgus surgery), in the setting of a limited array of perineural catheters (interscalene, femoral, and posterior popliteal), have been studied. To date, no RCT has compared blind and stimulating catheters for other orthopedic procedures and other types of nerve blocks (cervical paravertebral, thoracic paravertebral, SCB, ICB, AXB, lumbar plexus, transgluteal/ subgluteal/ lateral midfemoral/ lateral popliteal SB). Moreover, no study has formally compared the equipment available for stimulating catheter insertion. RCTs have used alternately different kits: the Arrow StimuCath Continuous Nerve Block Set (Arrow International, Reading, PA, USA); ${ }^{23-25,27}$ an $18 \mathrm{G}, 85-\mathrm{mm}$ long needle, oversheathed with a plastic introducer set (Multiplex, Vygon, France); ;8,29 a 50-mm, 18G needle with a stimulating catheter (Polymedic C-50 K +); ${ }^{26}$ or a $22 \mathrm{G}$, stimulating catheter with a $19.5 \mathrm{G}, 100-\mathrm{mm}$ needle set (Stimulong Plus, Pajunk, Geisingen, Germany).$^{30}$ Further studies are required to compare the electrical properties of these kits.

\section{Limitations}

For practical reasons, a decision was taken not to include ambulatory pumps in this narrative review. Although outpatient perineural LA infusions have 
TABLE III Elements of adjunctive ultrasonography and stimulating perineural catheters warranting further investigation

\begin{tabular}{ll}
\hline Adjunctive & Comparison of NS and US for: CPVB, ISB, \\
Ultrasonography & SCB, ICB, brachial canal block, LPB, SB using \\
& approaches other than the subgluteal and \\
& posterior popliteal approaches \\
- & Comparison of NS and US for perineural \\
& catheter insertion \\
- & Comparison of palpation- and US-guided \\
& epidural blocks \\
- & Comparison of blind and stimulating catheters \\
Perineural & for orthopedic surgical procedures other than \\
Catheters & shoulder surgery, TKR, ACL repair and hallux \\
& valgus correction \\
- & Comparison of blind and stimulating catheters \\
& for CPVB, TPVB, SCB, ICB, AXB, LPB and \\
& SB using approaches other than the posterior \\
& popliteal approach \\
- & Comparison of the different commercially \\
& available kits for stimulating perineural catheter \\
insertion
\end{tabular}

$\mathrm{ACL}=$ anterior cruciate ligament; $\mathrm{AXB}=$ axillary block; $\mathrm{CPVB}=$ cervical paravertebral block; ICB = infraclavicular block; ISB = interscalene block; LPB = lumbar plexus block; NS = neurostimulation; $\mathrm{SB}=$ sciatic block; $\mathrm{SCB}=$ supraclavicular block; TPVB = thoracic paravertebral block; TKR = total knee replacement; US = ultrasonography.

revolutionized the practice of ambulatory anesthesia, the data derived from the eight RCTs dealing with this topic would have been difficult to interpret. ${ }^{31-38}$ While five RCTs discharged patients on the day of surgery, ${ }^{32,34-37}$ three studies involved patient admission to hospital for the first night following surgery. ${ }^{31,33,38}$ Presumably, in these subjects, such a decision had an impact on the quality of data recording. While most RCT protocols examined ropivacaine $0.2 \%$ infusions, one study evaluated bupivacaine $0.25 \% .{ }^{36}$ More importantly, a total of six different types of ambulatory pumps were used in these eight RCTs. Ilfeld et al..$^{39-41}$ have repeatedly demonstrated that infusion rate accuracy differed significantly among various pumps, exhibiting flow rates within $15 \%$ of their expected rate for $18-100 \%$ of the infusion duration.

For this review, no attempt was made to perform a meta-analysis. In our view, heterogeneity would have been far too great to have supported such a systematic pooling of data.

\section{Conclusions}

For axillary blocks, US guidance yields a higher success rate than a double-injection, transarterial and a triple-stimulation technique. Compared to a quadruple-stimulation technique, no differences were found. The addition of NS to US guidance offers no clear benefits for AXB. For femoral blocks, compared to neurostimulation, echoguidance is associated with a LA sparing effect (up to $42 \%$ ). In children, US guidance yields a LA sparing effect and a longer duration of action for lower extremity nerve blocks.

Compared to their blind counterparts, stimulating perineural catheters seem to provide limited clinical benefits because of their minimal impact on patient satisfaction, procedural pain, performance time, success rate of the block, static/dynamic pain scores, and physiotherapy performance. The use of stimulating catheters is associated with a marked reduction in LA and opioid consumption. However, the benefits of this sparing effect remain uncertain, as they are not associated with a decrease in side effects or with analgesia-related costs.

A critical survey of the available RCTs can provide an effective tool to establish recommendations pertaining to the use of adjunctive US and stimulating perineural catheters. However, caution should be exercised when interpreting the limited data available in the literature. Despite current best evidence, many issues regarding these recent advances in regional anesthesia remain unresolved and, thus, warrant further elucidation through well-designed and meticulously conducted RCTs (Table III).

\section{References}

1 Soeding PE, Sha S, Royse CE, Marks P, Hoy G, Royse $A G$. A randomized trial of ultrasound-guided brachial plexus anaesthesia in upper limb surgery. Anaesth Intensive Care 2005; 33: 719-25.

2 Williams SR, Chouinard P, Arcand G, et al. Ultrasound guidance speeds execution and improves the quality of supraclavicular block. Anesth Analg 2003; 97: 1518-23.

3 Marhofer P, Sitzwohl C, Greher M, Kapral S. Ultrasound guidance for infraclavicular brachial plexus anesthesia in children. Anaesthesia 2004; 59: 642-6.

4 Marhofer P, Schrogendorfer K, Koinig H, Kapral S, Weinstabl C, Mayer N. Ultrasonographic guidance improves sensory block and onset time of three-in-one blocks. Anesth Analg 1997; 85: 854-7.

5 Marhofer P, Schrogendorfer K, Wallner T, Koinig H, Mayer N, Kapral S. Ultrasonographic guidance reduces the amount of local anesthetics for 3-in-1 blocks. Reg Anesth Pain Med 1998; 23: 584-8.

6 Willschke H, Marhofer P, Bosenberg A, et al. Ultrasonography for ilioinguinal/ iliohypogastric nerve blocks in children. Br J Anaesth 2005; 95: 226-30.

7 Hannan L, Reader A, Nist R, Beck M, Meyers WJ. The use of ultrasound for guiding needle placement for inferior alveolar nerve blocks. Oral Surg Oral Med Oral Pathol Oral Radiol Endod 1999; 87: 658-65. 
8 Grau T, Leipold RW, Conradi R, Martin E, Motsch $J$. Ultrasound imaging facilitates localization of the epidural space during combined spinal and epidural anesthesia. Reg Anesth Pain Med 2001; 26: 64-7.

9 Grau T, Leipold RW, Conradi R, Martin E, Motsch J. Efficacy of ultrasound imaging in obstetric epidural anesthesia. J Clin Anesth 2002; 14: 169-75.

10 Grau T, Leipold RW, Conradi R, Martin E. Ultrasound control for presumed difficult epidural puncture. Acta Anaesthesiol Scand 2001; 45: 766-71.

11 Grau T, Leipold RW, Fatehi S, Martin E, Motsch J. Real-time ultrasonic observation of combined spinalepidural anaesthesia. Eur J Anaesthesiol 2004; 21 : 25-31.

12 Willschke H, Marhofer P, Bosenberg A, et al. Epidural catheter placement in children: comparing a novel approach using ultrasound guidance and a standard loss-of-resistance technique. Br J Anaesth 2006; 97 : 200-7.

13 Birnbaum J, Kip M, Spies CD, et al. The effect of stimulating versus nonstimulating catheters for continuous interscalene plexus blocks in short-term pain management. J Clin Anesth 2007; 19: 434-39.

14 Liu FC, Lion JT, Tsai YF, et al. Efficacy of ultrasoundguided axillary brachial plexus block: a comparative study with nerve stimulator-guided method. Chang Gung Med J 2005; 28: 396-402.

15 Sites BD, Beach $M L$, Spence BC, et al. Ultrasound guidance improves the success rate of a perivascular axillary plexus block. Acta Anaesthesiol Scand 2006; 50: 678-84.

16 Tran DQ Clemente A, Doan J, Finlayson RJ. Brachial plexus blocks: a review of approaches and techniques. Can J Anesth 2007; 54: 662-74.

17 Chan VW, Perlas A, McCartney CJ, Brull R, Xu D, Abbas $S$. Ultrasound guidance improves success rate of axillary brachial plexus block. Can J Anesth 2007; 54: 176-82.

18 Casati A, Danelli $G$, Baciarello $M$, et al. A prospective, randomized comparison between ultrasound and nerve stimulation guidance for multiple injection axillary brachial plexus block. Anesthesiology 2007; 106: 992-6.

19 Casati A, Baciarello M, Di Cianni S, et al. Effects of ultrasound guidance on the minimum effective anaesthetic volume required to block the femoral nerve. Br J Anaesth 2007; 98: 823-7.

20 Domingo-Triado V, Selfa S, Martinez F, et al. Ultrasound guidance for lateral midfemoral sciatic nerve block: a prospective, comparative, randomized study. Anesth Analg 2007; 104: 1270-4.

21 Pianezza A, Gilbert ML, Minville V, et al. A modified mid-femoral approach to the sciatic nerve block: a cor- relation between evoked motor response and sensory block. Anesth Analg 2007; 105: 528-30.

22 Oberndorfer U, Marhofer P, Bosenberg A, et al. Ultrasonographic guidance for sciatic and femoral nerve blocks in children. Br J Anaesth 2007; 98: 797-801.

23 Stevens MF, Werdehausen R, Golla E, et al. Does interscalene catheter placement with stimulating catheters improve postoperative pain or functional outcome after shoulder surgery? A prospective, randomized and double-blinded trial. Anesth Analg 2007; 104: 442-7.

24 Salinas FV, Neal JM, Sueda LA, Kopacz DJ, Liu SS. Prospective comparison of continuous femoral nerve block with nonstimulating catheter placement versus stimulating catheter-guided perineural placement in volunteers. Reg Anesth Pain Med 2004; 29: 212-20.

25 Hayek SM, Ritchey RM, Sessler D, et al. Continuous femoral nerve analgesia after unilateral total knee arthroplasty: stimulating versus nonstimulating catheters. Anesth Analg 2006; 103: 1565-70.

26 Dauri M, Sidiropoulou T, Fabbi E, et al. Efficacy of continuous femoral nerve block with stimulating catheters versus nonstimulating catheters for anterior cruciate ligament reconstruction. Reg Anesth Pain Med 2007; 32: 282-7.

27 Morin AM, Eberhart LHJ, Behnke HK, et al. Does femoral nerve catheter placement with stimulating catheters improve effective placement? A randomized, controlled, and observer-blinded trial. Anesth Analg 2005; 100: 1503-10.

28 Casati A, Fanelli G, Koscielniak-Nielsen Z, et al. Using stimulating catheters for continuous sciatic nerve block shortens onset time of surgical block and minimizes postoperative consumption of pain medication after halux valgus repair as compared with conventional nonstimulating catheters. Anesth Analg 2005; 101 : 1192-7.

29 Casati A, Fanelli G, Danelli G, et al. Stimulating or conventional perineural catheters after hallux valgus repair: a double-blind, pharmaco-economic evaluation. Acta Anaesthesiol Scand 2006; 50: 1284-9.

30 Rodriguez J, Taboada M, Carceller J, Lagunilla J, Barcena M, Alvarez J. Stimulating popliteal catheters for postoperative analgesia after hallux valgus repair. Anesth Analg 2006; 102: 258-62.

31 Klein SM, Grant $S A$, Greengrass $R A$, et al. Interscalene brachial plexus block with a continuous catheter insertion system and a disposable infusion pump. Anesth Analg 2000; 91: 1473-8.

32 Ilfeld BM, Morey TE, Wright TW, Chidgey LK, Enneking FK. Continuous interscalene brachial plexus block for postoperative pain control at home: a 
randomized, double-blinded, placebo-controlled study. Anesth Analg 2003; 96: 1089-95.

33 Ilfeld BM, Vandenborne K, Duncan PW, et al. Ambulatory continuous interscalene nerve blocks decrease the time to discharge readiness after total shoulder arthroplasty: a randomized, triple-masked placebo-controlled study: a randomized, double-blinded, placebo-controlled study. Anesthesiology 2006; 105: 999-1007.

34 Ilfeld BM, Morey TE, Enneking FK. Continuous infraclavicular brachial plexus block for postoperative pain control at home: a randomized, double-blinded, placebo-controlled study. Anesthesiology 2002; 96 : 1297-1304.

35 Ilfeld BM, Morey TE, Wang RD, Enneking FK. Continuous popliteal sciatic nerve block for postoperative pain control at home: a randomized, double-blinded, placebo-controlled study. Anesthesiology 2002; 97: 959-65.

36 White PF, Issioni T, Skrivanek GD, Early JS, Wakefield $C$. The use of a continuous popliteal sciatic nerve block after surgery involving the foot and ankle: does it improve the quality of recovery? Anesth Analg 2003; 97: 1303-9.

37 Zaric D, Boysen K, Christiansen J, Haastrup U, Kofoed $H$, Rawal N. Continuous popliteal sciatic nerve block for outpatient foot surgery - a randomized, controlled trial. Acta Anaesthesiol Scand 2004; 48: 337-41.

38 Capdevila X, Dadure C, Bringuier S, et al. Effect of patient-controlled perineural analgesia on rehabilitation and pain after ambulatory orthopedic surgery: a multicenter randomized trial. Anesthesiology 2006; 105: 566-73.

39 Ilfeld BM, Morey TE, Enneking FK. The delivery rate accuracy of portable infusion pumps used for continuous regional anesthesia. Anesth Analg 2002; 95: 1331-6.

40 Ilfeld BM, Morey TE, Enneking FK. Delivery rate accuracy of portable, bolus-capable infusion pumps used for patient-controlled continuous regional analgesia. Reg Anesth Pain Med 2003; 28: 17-23.

41 Ilfeld BM, Morey TE, Enneking FK. Portable infusion pumps used for continuous regional analgesia: delivery rate accuracy and consistency. Reg Anesth Pain Med 2003; 28: 424-32. 